\title{
Much Ado About Nothing? Demographic Bulges, the Productivity Puzzle and CPP Reform*
}

\author{
Herb Emery \\ Department of Economics \\ University of Calgary \\ Calgary, AB \\ Canada \\ T2N 1N4
}

\author{
Ian Rongve \\ Department of Economics \\ University of Regina \\ Regina, SK \\ Canada \\ S4S 0A2
}

August 1996

\begin{abstract}
Scholars and policy makers forecast that future demographically driven financial imbalances will undermine the political and financial sustainability of pay-as-you-go social insurance arrangements like the Canada Pension Plan (CPP). Proposed reforms for the CPP primarily involve reducing the benefits provided, hence reducing liabilities, and/or raising the taxes levied on labour income which finance the arrangement. The purpose of this paper is to demonstrate in an overlapping generations framework how demographic factors not only affect taxes required to finance the prescribed benefits, but also wages. While there may be fewer workers supporting more retirees in the future, it may also be the case that the incomes of those workers will rise substantially over the same time period leaving them much better able to afford the required taxes.
\end{abstract}

-We thank Pierre Tu, Livio di Matteo, Jeannine Farazli, Peter Townley, Gary Tompkins and seminar participants at the University of Winnipeg for comments. 


\section{Introduction}

The future of the Canada Pension Plan, which is financed on pay-as-yougo principles (where current revenues are spent to meet current costs), is far from certain. Scholars and policy makers often express the opinion that as members of the baby boom generation age and approach retirement, the CPP is not financially and/or politically sustainable in its current form. This conclusion follows because the costs of providing promised CPP benefits to this large cohort in their twilight years will be borne by a much smaller trailing cohort. The following cohorts may not be able to pay, or may choose to not honour, the levels of benefits promised by the current benefit formulas. These forecasts of future demographically driven financial imbalances have encouraged debates over how to reform existing pay-as-you-go social insurance arrangements so that they will be politically and financially sustainable. Proposed reforms for these programs primarily involve either reducing the benefits provided, hence reducing liabilities, and/or raising the taxes levied on labour income which finance the system. It may be, however, that nothing will need to be done and that the underlying assumptions of these forecasts are flawed. The purpose of this paper is to demonstrate in an overlapping generations framework how demographic factors not only affect taxes required to finance the prescribed benefits, but also affect wages. While there may be fewer workers supporting more retirees in the next 10 to 20 years, it may also be the case that the incomes of those workers will rise substantially over the same time period leaving them much better able to afford the required taxes.

Discussions of the impending pension crisis for the CPP focus on the in- 
crease in wage taxes necessary to support the benefits outlined under current benefit formulas for the CPP. A contribution rate of $3.6 \%$ prevailed from the introduction of the CPP in 1966 to 1986 . By 1993, the contribution rate had risen to $5 \%$ and is expected to increase to $14.2 \%$ by 2030 (Canada/Provincial Information Paper, 1996). To fund essentially the same level of benefits for a representative CPP recipient, a larger tax payment will be required from each member of the smaller baby bust cohort.

Clearly, this anticipated increase in taxes is troubling if real wages of the cohort of workers trailing the baby boomers do not increase. However if productivity, hence real wages, rises in the future then there will be a greater capacity to pay CPP benefits at the higher contribution rates (Pesando 1993, Bohn 1996). Bohn (1996, p. 5) points out that if real wages in the United States grow by an annual rate of $1.5 \%$, which is the U.S. Social Security administration's optimistic scenario, then real incomes will rise by $50 \%$ over the next 30 years. Bohn then calculates that if over the next 30 years pre-tax per capita income in the U.S. rises from $\$ 30,000$ to $\$ 45,000$ and taxes increase from $30 \%$ to $40 \%$, then real disposable income will still rise from $\$ 21,000$ to $\$ 27,000$ even with the higher tax rate. Thus, even with modest (and historically low) growth in real wages, at higher tax rates (or contribution rates) "future generations would be able to carry a rising fiscal burden and still be better off than we are." Pesando (1993), in looking at the Canada Pension Plan, makes the same point, if productivity "increases by just $1 \%$ per year, then by 2030 real GNP in Canada will be almost $50 \%$ higher than it is now, other things being equal. The capacity for the economy in 2030 to sustain the level of promised pension benefits will be enhanced accordingly."

\footnotetext{
${ }^{1}$ Page 11. Pesando notes that output per employee in Canada grew $1.1 \%$ per year from
} 
Thus, it is not clear that higher contribution rates for the smaller post-baby boom cohort to fund the currently "promised" Social Security and Canada Pension Plan benefits in the U.S. and Canada means that the pay-as-you-go plans are unsustainable, nor even that the following cohort will be worse off than the baby boom cohort. It may be justifiable to use this as a worst-case benchmark and expect the actual outcome to be substantially better.

Any conclusions we make about the future of a pay-as-you-go financed CPP depend crucially on what we believe about future productivity growth. Pay-as-you-go finance for social security arrangements like the CPP make sense when the growth in real wages exceeds the real interest rate. In the Federal/Provincial Information Paper on the CPP (1996, p. 19) a reversal in this relationship over the last 30 years is the driving force behind the desire for reforming the CPP:

In the 1960 s and 1970 s, the growth in real wages and salaries was very high -5.1 and 4.8 per cent. It exceeded the real rate of interest. By the 1980s and continuing into the 1990s, this situation had reversed. Interest rates were higher than the growth of wages. Today, it would be imprudent to assume any change in that relationship for the foreseeable future.

Thus, the Canadian governments must be assuming that the relationship between real wage growth and the real rate of interest is not affected by demographics. If this relationship is affected by demographics, then the governments' assumption of no change in the foreseeable future may be misguided rather than prudent. If reforms of the CPP are costly, and real wage

1981 to 1990 and that this growth was well below the historic average of $2.5 \%$. 
growth is higher than the real rate of interest in the future, then reforms to the CPP may not be for the better.

There are many reasons to suspect that the same demographic forces that are apparently threatening the sustainability of the status quo of payas-you-go social insurance, may be behind the slowdown of productivity in Canada and the United States. Since 1973 real wages and labour productivity have stagnated in North America after two decades of rapid growth. Coincident with these developments, the baby boom generation entered the labour force. Not only were more males entering the labour force, the women of the baby boom generation entering the labour force at a higher rate than women of previous generations. Welch (1979) found that the arrival of baby boomers in the U.S. labor market over the period 1967-75 coincided with a drop in the earnings of entrant workers relative to more experienced workers. Welch concludes that large cohorts depress earnings with most of the effects coming early in worker's career. Berger (1985), addressing Welch (1979), found that not only were earnings depressed at entry into the labor market for large cohorts, the negative effect upon earnings worsened with experience. Stapleton and Young (1984) also find a negative cohort size effect on wages using data from the period 1967-1990. They found, however, that the effect was primarily on the earnings of college educated males. In summary, there is strong evidence that there are significant cohort size effects on earnings. To date, however, we have only witnessed the effects of the entrance of a large cohort into the labor market and we can only speculate as the effects of the withdrawal of the same large cohort at retirement.

There are some predictions, however, about what will happen when the baby boomers retire. Summers (1993) (reporting his own estimates from 
earlier work) estimates that the increase in the number of old people in OECD countries over the next 40 years will result in a decline of per capita real income of about $10 \% .^{2}$ At the same time, Summers (1993) suggests that a shift in population density toward older age groups, while increasing the proportion of dependent population, will raise per capita productivity since fewer workers will be using "the given capital stock". This increase in per capita productivity may raise per capita real income. Yoo (1994) also concludes that the retirement of the baby boomers need not imply diminished standards of living.

Of course, tempering these effects are the potential problems arising from pay-as-you-go pension transfers reducing savings in the economy by transferring income from young 'savers' to old 'consumers'. Such transfers reduce the rate of capital formation (hence Summers' "given capital stock") which slows productivity and real wage growth. ${ }^{3}$ Obviously the magnitude of this effect increases as the dependency ratio rises. If the slowing effect on productivity of reduced savings dominates, then Kotlikoff (1996) argues young people face the double 'whammy' of low wages and high tax rates. Thus whether or not productivity and real wages rise as the baby boomers retires cannot be predicted a priori.

There is really nothing novel about hypothesizing the baby boom cohort directly impacted on labour productivity. In addition to Summers (1993), discussed above, Kotlikoff (1992) describes the tragedy of the baby boomers as follows; they bid their wages down due to highly competitive labour mar-

\footnotetext{
${ }^{2}$ Related to Bohn's (1996) and Pesando's (1993) arguments, Summers calculates that this decline can be fully compensated for if productivity grows at $0.2 \%$ per year or if the retirement age increases by 3 to 4 years.

${ }^{3}$ Kotlikoff (1996)
} 
kets, and when they go to consume out of their savings, they lose again from a depressed return to savings as they all sell their assets at once. The impact of the baby boom cohort on housing markets and housing prices has received considerable attention. ${ }^{4}$ Fair and Dominguez (1991) have studied the impact of demographic variables on macroeconomic variables. ${ }^{5}$

Our goal in this paper is to examine how demographic factors on their own could explain much of the observed changes in productivity/wage growth of the last 30 years and to use this to examine the impact of demographic factors on a pay-as-you-go financed CPP. We examine the impact of a relatively large cohort within an overlapping generations model. We show that as a large cohort enters the labour market in a closed economy, the real wage falls. When the same cohort withdraws from the labour market, real wages for the following cohort rise substantially. Including a pay-as-you-go pension with a fixed benefit, allows us to replicate the current predictions about higher contribution rates arising from the increase in the dependency ratio as baby boomers retire, but it also allows us to show that the cohorts following the baby boom cohort have strictly higher consumption and utility in both periods of their lives than the members of the baby boom cohort. Indeed, if the real world resembles our closed economy model at all, it may be justified and socially preferable, to raise future social insurance contribution rates even more than necessary to fund current promised benefits to pay baby boomers a more generous pension than currently prescribed. ${ }^{6}$

\footnotetext{
${ }^{4}$ See for example Manchester (1989) or Mankiw and Weil (1989)

${ }^{5}$ Because their findings for real wage performance as a function of the age composition of the economy were opposite to what they expected, they interpreted their findings as less than encouraging.

${ }^{6}$ This would be the intergenerational equivalent of a progressive tax and transfer scheme. Most people seem to view this as a desirable property within a generation so
} 
Our intention is not to provide a justification of pay-as-you-go systems. Justifications for such systems usually involve some type of intergenerational risk sharing, since we have have no uncertainty in our model this justification cannot be used. We are examining the problem of how to pay for a social security system once it is determined to be a desirable thing. In this situation it is appropriate to ignore the uncertainty because governments are considered to be risk neutral, thus dealing in certainty equivalents does capture all of the important elements of the problem.

\section{An Intergenerational Transfer Model}

In this section, we introduce a theoretical model that we use. It is an overlapping generations model where, in any given time period, there are two generations alive. We include a simple pay-as-you-go system of social security and this allows us to consider the general equilibrium dynamics of the baby-boom on the social security sytem. This work builds upon previous work that either analyses the dynamics utilizing a partial equilibrium framework, such as in Richardson (1994) or Wolfson and Murphy (1996), or the steady-state in a general equilibrium framework, such as Kotlikoff (1979) or Burbidge (1983). The model we use is actually a special case of the Burbidge (1983) model. Our model is much in the same spirit as Yoo (1994) which examines the economic effects of the baby boom in three models of economic growth including an over-lapping generations framework. Yoo, however, does not include a social security system and is also unable to comment on some of the within-period intergenerational issues. Jensen and Nielson (1993)

it may be reasonable to apply this principle across generations as well. 
examine the economic impacts of an aging population in an overlapping generations framework but their model has fixed wages and interest rates under a small open economy assumption. Bovenberg, Broer and Westerhout (1993) examine the effects of a unilateral temporary decline in fertility on a small open economy using an applied general equilibrium model of the Netherlands, but their model is not an overlapping generations formulation.

\subsection{Consumers}

In our model, agents born at any given time $t$, live for two periods; $t$ and $t+1$. At any time $t$, there are $N_{t}$ young agents born at time $t$ and $N_{t-1}$ old agents who were born in the previous period $t-1$.

There is one good produced in the economy. Consumers get utility from consuming this good in both their young period and their old period. Denote the consumption of each member of generation $t$ in period $t$ as $c_{t}(t)$ and in period $t+1$ by $c_{t}(t+1)$. Consumers supply one unit of labour inelastically in period $t$ for which they receive a wage of $w_{t}$ in time $t$. Thus, their income in time $t$ is equal to the wage rate $w_{t}$. In addition to financing consumption, consumers in their first period must also save a portion of their income, $s_{t}(t)$, and pay a social security contribution, $\theta_{t} w_{t}$. Thus, the budget constraint facing a young person is:

$$
c_{t}(t)+s_{t}(t)+\theta_{t} w_{t} \leq w_{t}
$$

Old consumers get income from two sources. The first is the return on their savings. In the second period this capital earns a return equal to $r_{t+1}$ The second source of income is the social security payment which is denoted $\tau_{t+1}$. Out of this income the consumer must finance consumption in the 
second period of his life, $c_{t}(t+1)$. Thus, the second period budget constraint for a consumer of generation $t$ is:

$$
c_{t}(t+1) \leq \tau_{t+1}+r_{t+1} s_{t}(t)
$$

The consumer maximizes a utility function which for analytical convenience is given by:

$$
U\left(c_{t}(t), c_{t}(t+1)\right)=\log \left(c_{t}(t)\right)+\log \left(c_{t}(t+1)\right)
$$

Thus, the consumers problem can be expressed as:

$$
\max _{c_{t}(t), c_{t}(t+1), s_{t}(t)} \log \left(c_{t}(t)\right)+\log \left(c_{t}(t+1)\right)
$$

subject to

$$
c_{t}(t)+s_{t}(t)+\theta_{t} w_{t} \leq w_{t}
$$

and

$$
c_{t}(t+1) \leq \tau_{t+1}+r_{t+1} s_{t}(t)
$$

The above problem can be simplified by recognizing that, since utility is increasing in consumption, the constraints will hold with equality. Thus, we can simplify our representation of the consumer's problem to:

$$
\max _{\mathbf{s}_{\mathbf{t}}(t)} \log \left(w_{t}-\theta_{t} w_{t}-s_{t}(t)\right)+\log \left(\tau_{t+1}+r_{t+1} s_{t}(t)\right)
$$

This problem produces the first order condition:

$$
\frac{c_{t}(t+1)}{c_{t}(t)}=r_{t+1}
$$

which can be solved to yield

$$
s_{t}^{*}(t)=\frac{w_{t}\left(1-\theta_{t}\right)}{2}-\frac{\tau_{t+1}}{2 r_{i+1}}
$$

Consumption in either period can now be determined by the budget constraints. 


\section{$2.2 \quad$ Firms}

There is one firm in the economy. It produces output using capital and labour with production technology characterized by constant returns to scale. We represent this production technology with a Cobb-Douglas production function:

$$
y_{t}=\gamma l_{t}^{\alpha} k_{t}{ }^{1-\alpha}
$$

where $y_{t}$ is total production in time $t ; l_{t}$ is the labour used in time $t$, and $k_{t}$ is the total capital stock in time $t$. In equilibrium all factor markets clear so $l_{t}=N_{t}$ and $k_{t}=N_{t-1} s_{t-1}(t-1)$. Because of constant returns to scale technology the capital and labour inputs will be paid their marginal product so:

$$
w_{t}=\gamma \alpha l_{t}^{\alpha-1} k_{t}^{1-\alpha}
$$

and

$$
r_{t}=\gamma(1-\alpha) l_{t}^{\alpha} k_{t}{ }^{-\alpha}
$$

Substituting from the equilibrium conditions leaves the following two difference equations:

$$
w_{t}=\gamma \alpha\left[\frac{N_{t-1}}{N_{t}}\left(\frac{w_{t-1}\left(1-\theta_{t-1}\right)}{2}-\frac{\tau_{t}}{2 r_{t}}\right)\right]^{1-\alpha}
$$

and

$$
r_{t}=\gamma(1-\alpha)\left[\frac{N_{t-1}}{N_{t}}\left(\frac{w_{t-1}\left(1-\theta_{t-1}\right)}{2}-\frac{\tau_{t}}{2 r_{t}}\right)\right]^{-\alpha}
$$

The two equations in (13) and (14) describe the factor markets which provide both income sources for the consumer. ${ }^{7}$

\footnotetext{
${ }^{7}$ Profits are zero and can be disregarded because of the assumption of constant returns to scale technology.
} 
Generally, equation (14) presents a problem as it does not have a closed form solution for $r_{t}$. To see this rewrite (14) as

$$
r_{t}^{1 / \alpha}\left(\frac{w_{t-1}\left(1-\theta_{t-1}\right)}{2}-\frac{\tau_{t}}{2 r_{t}}\right)=\frac{N_{t}}{N_{t-1}}[(1-\alpha) \gamma]^{1 / \alpha}
$$

Which can in turn be written as

$$
A r_{t}^{1 / \alpha}+B r_{t}^{1 / \alpha-1}+C=0
$$

where $A=\left(w_{t-1}\left(1-\theta_{t-1}\right)\right) / 2, B=-\tau_{t} / 2$ and $C=-[(1-\alpha) \gamma]^{1 / \alpha} N_{t} / N_{t-1}$. Equation (16) will only have a closed form solution when $\alpha=0.5$, in which case (16) is a quadratic equation. When $\alpha \neq 0.5$, numerical methods are required in the simulations to come to find the roots of the equilibrium condition. When numerical methods are used it is important to note that while $A$ does include the endogenous variable $w_{t-1}$, we only need to solve this problem in time $t$ when $w_{t-1}$ is already known.

\subsection{Social Security System}

The pay-as-you-go social security system in this model is an income redistribution system rather than a true pension (savings) plan. Weldon (1976) has argued that the proper way to examine a pay-as-you-go social security system is as an income transfer from the young workers to the older generation and not as a form of savings for retirement.

We model the social security system as imposing taxes $\theta_{t} w_{t}$ on each young worker at time $t$ and redistributing these revenues to each old consumer at $t$ as a transfer $\tau_{t}$. We impose a pay-as-you-go constraint that the plan must be self financing, and must produce zero excess revenue. This constraint takes the form

$$
N_{t} \theta_{t} w_{t}=N_{t-1} \tau_{t}
$$


We assume that the payments $\tau_{t}$ are set outside the model, probably by some governmental authority. Thus, for the social security sytem to break even it must be that the social security taxes are allowed to change from period to period. The current period tax per person must satisfy the following equation:

$$
\theta_{t}=\frac{N_{t-1}}{N_{t}} \frac{\tau_{t}}{w_{t}}
$$

Equation (18) closes the model. By solving (13), (14), and (18) for $w_{t}, r_{t}$, and $\theta_{t}$ we are able to determine all of the remaining elements of the model.

\subsection{Comparative Dynamics}

In this subsection we examine the comparative dynamics of the model to determine the economic impacts of changes in the age distribution of the population. For example, it is often argued that as the baby boom generation ages and starts to collect social security, the rate of social security tax will have to increase. We examine this claim and demonstrate that it is based upon a presumption of no effect of demographics on wages. Once this demographic effect is accounted for, the direction of change in the CPP contribution rate is ambiguous.

The objective here is to find the derivitives $\partial \theta_{t} / \partial D, \partial w_{t} / \partial D$, and $\partial r_{t} / \partial D$ where $D=N_{t-1} / N_{t}$ is the ratio of older consumers to younger consumers. We can rewrite equations (18), (13), and (14), for a given time period, in the more compact forms ${ }^{8}$

$$
\begin{aligned}
& \theta_{t}=\theta\left(D, w_{t}\right) \\
& w_{t}=w\left(D, r_{t}\right)
\end{aligned}
$$

\footnotetext{
${ }^{8}$ For notational convenience the time subscript on the right hand side has been suppressed.
} 
and

$$
r_{t}=r(D) .
$$

Combining the three equations, we can write the tax rate $\theta_{t}$ as

$$
\theta_{t}=\theta(D, w(D, r(D)))
$$

so that the equilibrium tax rate at a given time period is seen ultimately to be a function of exogenous or predetermined factors. The change in the wage rate when the demographics change is then

$$
\frac{\partial w_{t}}{\partial D}=w_{1}+w_{2} \frac{\partial r_{t}}{\partial D}
$$

and the change in the tax rate when the proportion of older consumers increases is then:

$$
\frac{\partial \theta_{t}}{\partial D}=\theta_{1}+\theta_{2}\left(w_{1}+w_{2} \frac{\partial r_{t}}{\partial D}\right)
$$

where $\theta_{1}$, and $\theta_{2}$ are the partial derivatives of function (19) with respect to the first and the second arguements respectively. $\theta_{1}$ is the direct effect of demographic change on the tax rate, while $\theta_{2}$ is the effect on the tax rate induced by changes in other economic variables. $w_{1}$ and $w_{2}$ are defined similarly. Current forecasts of the CPP tax increases presume that both $w_{1}$ and $w_{2}$ are zero, thus the only influence of demographics on the tax rate in the current forecasts is from the direct effect $\theta_{1}$.

Given our model, the derivatives of interest are:

$$
\begin{gathered}
\theta_{1}=\frac{\tau_{t}}{w_{t}}>0 \\
\theta_{2}=-D \frac{\tau_{t}}{w_{t}{ }^{2}}<0 \\
w_{1}=\gamma \alpha(1-\alpha)\left[D s_{t-1}\right]^{-\alpha} s_{t-1}>0
\end{gathered}
$$


and

$$
w_{2}=\gamma \alpha(1-\alpha)\left[D s_{t-1}\right]^{-\alpha} D \frac{\tau_{t}}{2 r_{t}^{2}}>0
$$

Now from equation (14) we have

$$
\gamma(1-\alpha)\left[D s_{t-1}\right]^{-\alpha}-r_{t}=0
$$

Applying the implicit function theorem to this equation we obtain

$$
\frac{\partial r_{t}}{\partial D}=\frac{-\gamma \alpha(1-\alpha)\left[D s_{t-1}\right]^{-(1+\alpha)}}{\gamma \alpha(1-\alpha)\left[D s_{t-1}\right]^{-(1+\alpha)} \tau^{2} /\left(2 r_{t}^{2}\right)+1}<0
$$

We can now find the signs of the other two derivatives of interest.

$$
\frac{\partial w_{t}}{\partial D}=(+)+(-)=?
$$

This is at first perhaps a surprising result. It says that as the number of workers fall, the wage rate can either rise or fall. The direction of change depends upon the responsiveness of savings to the change in the interest rate. We have seen that a rise in $D$ results in a fall in the equilibrium interest rate. Under perfect foresight, this will mean that the previous large generation will reduce their individual levels of saving. This may result in either a higher or lower capital-labour ratio for the subsequent smaller generation. A high responsiveness of saving to the interest rate will result in a lower capitallabour ratio, and thus a lower wage rate for the smaller following cohort.

It is possible to say something about the probable direction of change in the wage rate when the cohort size changes. Consider a cohort of consumers at time $t-1$ that is $10 \%$ larger than the cohort of young consumers who follow at time $t$. The larger cohort will have a smaller return to savings which will produce lower per-capita savings. The wage rate facing the younger cohort will only fall if the capital-labour ratio falls. Thus, for the wage rate to fall 
when the smaller generation begins work, the percentage fall in per-capita savings by the larger cohort must be larger than the $10 \%$ decline in the number of workers.

The percentage change in the capital stock arising from a one percent fall in the population will be

$$
\frac{\partial k_{t}}{\partial D} \frac{1}{k_{t}}=\eta_{s} \frac{\partial r_{t} / \partial D}{r_{t}}
$$

where $\eta_{s}$ is the interest elasticity of savings. Boskin (1978) estimates $\eta_{s}$ for the United States to be about 0.25 . This implies that for the capital labour ratio to fall when the smaller cohort starts working, equation (32) must be less than negative one, hence, we must have $\left(\partial r_{t} / \partial D\right) / r_{t}<-4$. Given historical movements in interest rates, this seems to be a much higher responsiveness of the interest rate than is reasonable. Thus, we conclude that the usual case will see wage rates rise in the period after a demographic bulge.

The central comparative dynamic result can now be determined. The sign of $\partial \theta_{t} / \partial D$ is given by

$$
\frac{\partial \theta_{t}}{\partial D}=(+)+(?)=?
$$

The sign is again uncertain, in partial contradiction to conventional wisdom that holds that it must be positive. What determines the sign? If the wage rate for the subsequent smaller generation falls, then the tax rate must rise. If the wage rate itself rises, then it may rise enough to permit a lower tax rate for the smaller generation. It is this element of our model that is the distinguishing feature compared to current forecasts for the CPP contribution rates.

Because the direction of change of the variables of interest are theoretically indeterminate, we perform some simulations of the model to determine 
(given reasonable parameter values) how the economy will react to a demographic bulge.

\section{Simulations}

In this section of the paper we provide the results of several simulations of the model. We focus the discussion upon two limiting cases of our modelled economy. First, we examine a closed economy representation of the model, followed by an open economy version. For each scenario we present two sets of results. The first is for a no social-security economy. In this case $\tau=0$ for all periods and the only source of retirement income is private savings. Obviously in this case the social-security tax rate is also zero in all periods. ${ }^{9}$ The second case we present is for $\tau=1.0$. In this case then the social-security tax rate must be determined in every period by solving equation (18).

\subsection{Closed Economy}

In this subsection we simulate the model under the assumption that the only capital available to the economy is from domestic savings. Technology in this simulation is given by the production function

$$
y_{t}=10 l_{t}{ }^{.65} k_{t}{ }^{.35}
$$

so that $\gamma=10$ and $\alpha=.65$. There is no significance to the choice of $\gamma$ as it merely scales all equilibrium values of wages, interest rates and social security taxes. $\alpha$ on the other hand is the share of output that goes to labour

\footnotetext{
${ }^{9}$ This situation can be regarded as the outcome of a fully funded pensions scheme as well.
} 
in equilbrium. A stylized fact of most industrialized economies is that the share of labour in national income is about two thirds, so .65 was chosen with that in mind. ${ }^{10}$ The baby boom is represented as a one-time-only increase in the population size. We present the results for the simulation when the bulge generation is $10 \%$ larger than the other generations. ${ }^{11}$

In simulating the model, we proceed as follows. First we determine the equilbrium interest rate from equation (14). Since this is a nonlinear equation with no closed form solution, the roots are found by utilizing a NewtonRaphson numerical method. A variety of reasonable starting values were chosen for the algorithm, and all produced the same value for the equilibrium interest rate. After the first period, the starting value chosen for all subsequent periods is the previous periods equilibrium rate.

Next, we substitute the equilbrium interest rate into equation (14) to obtain the equilibrium wage rate. The equilibrium wage rate is used in turn to obtain $\theta_{t}$, the social security tax rate required to generate a balanced budget for the social security system, from equation (18).

Once the equilbrium values of $r_{t}, w_{t}$, and $\theta_{t}$ are determined, we can use them to calculate savings, capital stock, and consumption for the individual generations.

The simulation was run through 100 generations. The baby-boom is generation 90 where the population size increases from 100 persons to 110 . The population size of generation 91 is again 100 persons. We chose our

\footnotetext{
${ }^{10}$ We have calculated the results for both $\alpha=.5$ and $\alpha=.75$. The results of these simulations are similar to those for $\alpha=.65$, hence are not reported. These results are available upon request from the authors.

${ }^{11}$ We have again run the simulations for larger bulges and obtained qualitatively the same results. The results of these other simulations are also available on request from the authors.
} 


\begin{tabular}{|l|l|l|l|l|l|l|l|}
\hline \hline gen & $k_{t}$ & $\theta_{t}$ & $w_{t}$ & $N_{t}$ & $r_{t}$ & $c_{t}(t)$ & $c_{t-1}(t)$ \\
\hline 88 & 613.0740 & 0.0000 & 12.2615 & 100 & 1.0769 & 6.1307 & 6.6023 \\
89 & 613.0740 & 0.0000 & 12.2615 & 100 & 1.0769 & 6.1307 & 6.6023 \\
90 & 613.0740 & 0.0000 & 11.8592 & 110 & 1.1458 & 5.9296 & 7.0243 \\
91 & 652.2560 & 0.0000 & 12.5302 & 100 & 1.0344 & 6.2651 & 6.1337 \\
92 & 626.5124 & 0.0000 & 12.3549 & 100 & 1.0619 & 6.1774 & 6.6526 \\
93 & 617.7443 & 0.0000 & 12.2941 & 100 & 1.0716 & 6.1470 & 6.6199 \\
94 & 614.7045 & 0.0000 & 12.2729 & 100 & 1.0751 & 6.1364 & 6.6085 \\
95 & 613.6442 & 0.0000 & 12.2655 & 100 & 1.0763 & 6.1327 & 6.6045 \\
96 & 613.2735 & 0.0000 & 12.2629 & 100 & 1.0767 & 6.1314 & 6.6031 \\
97 & 613.1438 & 0.0000 & 12.2620 & 100 & 1.0768 & 6.1310 & 6.6026 \\
98 & 613.0984 & 0.0000 & 12.2617 & 100 & 1.0769 & 6.1308 & 6.6024 \\
99 & 613.0825 & 0.0000 & 12.2615 & 100 & 1.0769 & 6.1308 & 6.6024 \\
100 & $613.0769 œ$ & 0.0000 & 12.2615 & 100 & 1.0769 & 6.1307 & 6.6023 \\
\hline \hline
\end{tabular}

Table 1: Closed Economy, 10\% Boom, $\tau=0$

economy's baby boom generation to be the ninetieth to allow the simulation to settle down to a steady-state before the bulge occurs. We also ran the simulation long enough after the bulge to allow the model to return to its steady-state.

Tables 1 and 2 present two sets of results. The first is for a no social security economy where $\tau=0$ for all periods and the only source of retirement income is private savings. Obviously in this case the social-security tax rate is also zero in all periods. The second case we present is for $\tau=1.0$. In this case then the social-security tax rate must be determined in every period by solving equation (18) The variables reported in the tables are as follows. $k_{t}$ is the amount of capital in the economy during time $t ; k_{t}$ also equals the total savings of the generation born in time $t-1, \theta_{t}$ is the social security tax rate that is required to pay a benefit of $\tau$ at time $t ; w_{t}$ is the wage rate at time $t$; $N_{t}$ is the size of the cohort born in time $t, r_{t}$ is the return on capital in time 
$t$; $c_{t}(t)$ is the consumption of the generation born in time $t$ in the first period of their lives, and $c_{t-1}(t)$ is the consumption of the generation born in time $t-1$ in the second period of their lives. The bulge generation is born in time 90 , the third line of the table.

The no social security system simulation results are presented in Table 1. First note the time path of wages. In times 88 and 89 , the wages are at their steady-state values. When the bulge generation begins to work, the relative supply of labour increases, pushing down the wage rate to 11.8592 from its steady-state value of 12.2615 . The post-bulge generation sees their wages rise to the extent that their wages are higher than the steady state wages. The reason for this is the amount of capital in the economy. The boomers, while saving less per person than do the previous generations, in total provide a higher capital stock to the post bulge generation. Thus, for the post-bulge generation labour is relatively more scarce than capital, leading to the higher wage rates, and thus higher first period income. In turn some of this income is saved resulting in slightly higher than steady-state capital stocks for succeeding generations.

The return to capital rises dramatically as the bulge generation enters the work force, reflecting the relative scarcity of capital. Subsequent periods however have a lower than steady-state return on capital because of the higher capital stock arising from the higher wage rate facing workers, and subsequently increased savings.

Now examine the pattern of consumption. As expected from the first order conditions we have consumption in the second period of life slightly higher than consumption in the first period. The cohort born in time 89 is the first to show the effect of the bulge generation in their consumption 
patterns. They are the beneficiaries of the high return on capital generated by the relative scarcity of capital in time 90 . Their consumption is higher in the second period as a result of this increased return on their savings, rising to 7.0243 from a steady-state value of 6.6023 .

The members of the bulge generation have lower than steady-state consumption in both periods of their lives. They consume 5.9296 in the first period, then 6.1337 in the second period. They face the 'tragedy' predicted by Kotlikoff (1992). In their first period they face low wage rates due to the relative surplus of labour, and then in the second period of their life they face low returns on their savings because of the low return on capital generated by the relative abundance of capital compared to labour.

The cohorts following the bulge all have higher levels of consumption than the steady-state. In the first period of life this is due to increased wage rates arising from the relative scarcity of labour, but in the second period, since the return on capital is actually below the steady-state return, the increased consumption for the following cohorts must be due to higher levels of savings, arising from the higher incomes in the first period of life.

The results from Table 1 indicate that both the generation immediately preceding the bulge, and the generation immediately succeeding the bulge are the big winners. Both see their consumption significantly increased as a result of the movements in the relative price of labour and capital.

Examining Table 2 we can see the effect of introducing a social security system into the economy. The social security system transfers some of the income of the young generation to the old generation. The immediate effect of this is to reduce the amount of savings by the young, and thus the capital available for the next generation to use in production as predicted by Kot- 


\begin{tabular}{|l|l|l|l|l|l|l|l|}
\hline \hline gen & $k_{t}$ & $\theta_{t}$ & $w_{t}$ & $N_{t}$ & $r_{t}$ & $c_{t}(t)$ & $c_{t-1}(t)$ \\
\hline 88 & 469.3078 & 0.0896 & 11.1667 & 100 & 1.2812 & 5.4736 & 7.0128 \\
89 & 469.3078 & 0.0896 & 11.1667 & 100 & 1.2812 & 5.4513 & 7.0128 \\
90 & 471.5388 & 0.0840 & 10.8183 & 110 & 1.3589 & 5.3614 & 7.4077 \\
91 & 500.2562 & 0.0963 & 11.4191 & 100 & 1.2291 & 5.5537 & 6.5898 \\
92 & 476.5381 & 0.0891 & 11.2266 & 100 & 1.2685 & 5.5051 & 7.0451 \\
93 & 472.1500 & 0.0894 & 11.1903 & 100 & 1.2762 & 5.4860 & 7.0255 \\
94 & 470.4284 & 0.0895 & 11.1760 & 100 & 1.2792 & 5.4785 & 7.0178 \\
95 & 469.7501 & 0.0895 & 11.1703 & 100 & 1.2804 & 5.4755 & 7.0148 \\
96 & 469.4825 & 0.0895 & 11.1681 & 100 & 1.2809 & 5.4744 & 7.0136 \\
97 & 469.3768 & 0.0895 & 11.1672 & 100 & 1.2811 & 5.4739 & 7.0131 \\
98 & 469.3350 & 0.0896 & 11.1669 & 100 & 1.2812 & 5.4737 & 7.0129 \\
99 & 469.3185 & 0.0896 & 11.1668 & 100 & 1.2812 & 5.4736 & 7.0129 \\
100 & 469.3120 & 0.0896 & 11.1667 & 100 & 1.2812 & 5.4736 & 7.0128 \\
\hline \hline
\end{tabular}

Table 2: Closed Economy, 10\% Boom, $\tau=1.0$

likoff (1979). This has the effect of making labour relatively more plentiful compared to the no social security case, as seen by the fall in $w_{t}$ between Table 1 and Table 2. There is also a corresponding increase in the rate of return on capital, since it is now relatively more scarce. These features of the economy lead to a consistent pattern of lower consumption by all cohorts in their first period of life, then higher consumption by all cohorts in their second period of life.

Examining the required social security tax rate, $\theta_{t}$ shows the effect of the bulge that many commentators have suggested. It is indeed true in a closed economy that to finance social security payments for the bulge generation, the tax rate must increase. We also see the required payment fall for the bulge generation because there are more of them to pay the social security of a smaller preceeding generation. ${ }^{12}$

\footnotetext{
${ }^{12}$ This could be related to the rapid increase in the benefit levels of the CPP through
} 
Thus far it appears that the concern over rising contribution rates is justified by the model. Required contribution rates do rise as the bulge generation retires, but it does not follow that reducing benefits is the answer. Notice that consumption for the post-bulge generations is still higher than the corresponding steady-state levels. The immediate post-bulge generation is still consuming at a higher level than the steady-state level. Notice also that for the generation born in period 92 , and subsequent generations, the contribution rate is lower than the steady-state level and consumption is higher. Regardless of the higher social security tax rate the immediate postbulge generation is still one of the two big winners from the bulge. As such, as Bohn (1996) points out, levying higher taxes on the post-bulge generation amounts to nothing more than taxing relatively well off future generations and transferring to the less well off baby boom generation.

A word can be inserted here concerning two important stylized facts of the North American economy in the last 20 years, high real interest rates and low real wage growth. We can see that these are exactly the two most fundamental predictions of our model. The last 20 years is the period when the baby boomers have been an important feature of the labour market. This corresponds to period 90 in our model, the time when the bulge generation is working. The model then predicts that over this period we will see the combination of high real interest rates and low real wage growth. There is some bad news in this, the model also predicts that these two things will continue to be a feature of our economy until the boomers start to retire which, realistically, will not begin to be felt for another 10-15 years.

Another stylized fact noted by Kotlikoff (1996) is that the ratio of the the seventies and eighties. 
consumption of seniors to the consumption of workers is very high at the current time. ${ }^{13}$ Again this is exactly the prediction of our model. The generation immediately preceding the bulge generation has tremendously high consumption in their second period of life. Unlike Kotlikoff, however, we cannot blame this on any intergenerational transfer policy because the same stylized fact occurs in the model with no social security system and thus no intergenerational transfers.

\subsection{Open Economy}

In this subsection we discuss the simulation of the model with perfectly mobile capital. We refer to this case, with capital free to enter and leave the country, as our open economy model. The stylized facts from the demographic bulge as before are quite different from those of the previous closed economy case.

The key feature of this model is that the return on capital, $r_{t}$, is determined in international markets and hence exogenous for the domestic economy. The level of capital used in production must then be free to fluctuate to maintain $r_{t}$. Instead of using equation (13) to solve for the equilibrium interest rate, we use it to solve for the amount of capital that must be in the economy to produce an equilibrium interest rate of $r_{t}$. The subsequent elements of the simulation remain identical to the closed economy version of the model.

One thing that is present in the open economy model that is not required in the closed economy model is savings by the rest of the world in the domes-

\footnotetext{
${ }^{13}$ Kotlikoff actually notes this for the US. We are sure the same thing holds true in the Canadian economy
} 


\begin{tabular}{|l|l|l|l|l|l|l|l|l|}
\hline \hline gen & $s^{r}$ & $\bar{k}_{t}$ & $\theta_{t}$ & $\overline{w_{t}}$ & $\overline{N_{t}}$ & $r_{t}$ & $c_{t}(t)$ & $c_{t-1}(t)$ \\
\hline 88 & 15.9356 & 637.4246 & 0.0000 & 12.4298 & 100 & 1.0500 & 6.2149 & 6.5256 \\
89 & 15.9356 & 637.4246 & 0.0000 & 12.4298 & 100 & 1.0500 & 6.2149 & 6.5256 \\
90 & 79.6781 & 701.1671 & 0.0000 & 12.4298 & 110 & 1.0500 & 6.2149 & 6.5256 \\
91 & -46.2133 & 637.4246 & 0.0000 & 12.4298 & 100 & 1.0500 & 6.2149 & 6.5256 \\
92 & 15.9356 & 637.4246 & 0.0000 & 12.4298 & 100 & 1.0500 & 6.2149 & 6.5256 \\
93 & 15.9356 & 637.4246 & 0.0000 & 12.4298 & 100 & 1.0500 & 6.2149 & 6.5256 \\
94 & 15.9356 & 637.4246 & 0.0000 & 12.4298 & 100 & 1.0500 & 6.2149 & 6.5256 \\
95 & 15.9356 & 637.4246 & 0.0000 & 12.4298 & 100 & 1.0500 & 6.2149 & 6.5256 \\
96 & 15.9356 & 637.4246 & 0.0000 & 12.4298 & 100 & 1.0500 & 6.2149 & 6.5256 \\
97 & 15.9356 & 637.4246 & 0.0000 & 12.4298 & 100 & 1.0500 & 6.2149 & 6.5256 \\
98 & 15.9356 & 637.4246 & 0.0000 & 12.4298 & 100 & 1.0500 & 6.2149 & 6.5256 \\
99 & 15.9356 & 637.4246 & 0.0000 & 12.4298 & 100 & 1.0500 & 6.2149 & 6.5256 \\
100 & 15.9356 & 637.4246 & 0.0000 & 12.4298 & 100 & 1.0500 & 6.2149 & 6.5256 \\
\hline \hline
\end{tabular}

Table 3: Open Economy, 10\% Boom, $\tau=0$

tic economy. This is denoted $s^{r}$ and is the difference between the required amount of capital and the previous generations savings.

$$
s^{r}=k_{t}-N_{t-1} s_{t-1}
$$

In national income accounting the quantity $s_{r}$ is known as the capital account surplus and is the amount of foreign investment in the domestic economy.

Tables 3 and 4 present the open economy simulation results for the same period covered by the closed economy results. The only difference in these two tables compared to the closed economy results is in column 2 where the savings from the rest of the world are presented.

Examining the simulation results with no social security system presented in Table 3, the striking result is that a demographic bulge has almost no impact on this economy. Wage rates, and consumption do not change from year to year. This is, of course, because to maintain the required interest rate, the 


\begin{tabular}{|l|l|l|l|l|l|l|l|l|}
\hline \hline gen & $s^{r}$ & $k_{t}$ & $\theta_{t}$ & $w_{t}$ & $N_{t}$ & $r_{t}$ & $c_{t}(t)$ & $c_{t-1}(t)$ \\
\hline 88 & 113.5547 & 637.4246 & 0.0805 & 12.4298 & 100 & 1.0500 & 6.1911 & 6.5006 \\
89 & 113.5547 & 637.4246 & 0.0805 & 12.4298 & 100 & 1.0500 & 6.1911 & 6.5006 \\
90 & 177.2971 & 701.1671 & 0.0731 & 12.4298 & 110 & 1.0500 & 6.2365 & 6.5006 \\
91 & 56.1677 & 637.4246 & 0.0885 & 12.4298 & 100 & 1.0500 & 6.1411 & 6.5484 \\
92 & 118.5547 & 637.4246 & 0.0805 & 12.4298 & 100 & 1.0500 & 6.1911 & 6.4481 \\
93 & 113.5547 & 637.4246 & 0.0805 & 12.4298 & 100 & 1.0500 & 6.1911 & 6.5006 \\
94 & 113.5547 & 637.4246 & 0.0805 & 12.4298 & 100 & 1.0500 & 6.1911 & 6.5006 \\
95 & 113.5547 & 637.4246 & 0.0805 & 12.4298 & 100 & 1.0500 & 6.1911 & 6.5006 \\
96 & 113.5547 & 637.4246 & 0.0805 & 12.4298 & 100 & 1.0500 & 6.1911 & 6.5006 \\
97 & 113.5547 & 637.4246 & 0.0805 & 12.4298 & 100 & 1.0500 & 6.1911 & 6.5006 \\
98 & 113.5547 & 637.4246 & 0.0805 & 12.4298 & 100 & 1.0500 & 6.1911 & 6.5006 \\
99 & 113.5547 & 637.4246 & 0.0805 & 12.4298 & 100 & 1.0500 & 6.1911 & 6.5006 \\
100 & 113.5547 & 637.4246 & 0.0805 & 12.4298 & 100 & 1.0500 & 6.1911 & 6.5006 \\
\hline \hline
\end{tabular}

Table 4: Open Economy, 10\% Boom, $\tau=1.0$

capital-labour ratio must also be held constant which in turn ensures relative wages remain the same. Since the individuals in the different generations are the same, faced with the same problem they make the same allocation of resources between periods.

The only areas where the bulge is apparent is in the capital stock, and in the quantity of required savings from the rest of the world. The required capital stock for period 90 rises by $10 \%$, because the quantity of labour increase by $10 \%$, to maintain the capital labour ratio. This requires a larger inflow of capital into the economy in period 90 compared to previous time periods. Because of the larger number of individuals saving in the boomer generation, the economy has an excess of capital in period 91 , leading to a net outflow of capital in this period. In period 92 the economy is again back in the long term situation with a minor inflow of capital in every period.

Table 4 presents the results for the case when a social security system is 
in place. As in the closed economy case the initial effect of the transfer of income from the young to the old is to reduce the amount of domestic savings compared to the no social security case. This shows up as a higher required capital inflow relative to the no social-security case. Again the effect of the bulge is to increase this required capital inflow. In the subsequent period a smaller capital inflow is seen due to the increased quantity of aggregate savings by the bulge generation in this period. Unlike in the no social security case, the effects of the bulge extend for another period. Again in period 92 we see an increase in the required capital inflow relative to the long run values.

The secret behind the difference in the two cases is seen by examining the required social-security tax rate. Individuals in the bulge generation have the same wage rate as any other generation but there are more individuals available to help meet the fixed social-security payment. This means that members of this generation face a lower tax rate in their first period of life and thus can save more of their income. The immediate post-bulge generation must cover social security payments to this larger generation which results in less savings when the post-bulge generation is young and a corresponding increase in the required capital inflow in the period when this generation is old.

Now examine consumption. Unlike the closed economy case, no generation prior to the bulge generation is affected at all by the presence of the bulge. The bulge generation sees consumption in both periods higher than the steady-state values. The reason for this is that with the lower tax rate they are able to both consume, and save, more in their first period. The higher savings translate into higher consumption in the second period as well. The immediate post-bulge generation faces the mirror situation of 
higher tax rates forcing lower consumption, and saving, in the first period, followed by lower consumption in the second period due to the low amount of savings.

As with the closed economy version of the model, we can relate these results to one of the important stylized facts of the North American economy over the last 20 years. The capital account surplus, and associated current account deficit, in both Canada and the United States has grown substantially over the last 10-15 years. This reflects a large increase in the amount of foreign savings that are being utilized in production. In both Table 3 and Table 4 this is a feature of the time period when the bulge generation is in the labour force. The model again suggests that this will be a feature of the economy until the baby boomers begin to retire in ten to fifteen years.

\section{Implications for the CPP}

This paper provides some insight into the current debate on the reform of pay-as-you-go financed CPP. For example there are several suggestions being made for reforming the Canada Pension Plan. These include increasing contributions now, to at least partially fund the retirement payments to the baby-boomers, and lowering benefits. We conclude that whether or not rising contribution rates to finance future social security benefits is desirable depends upon several factors; future real wages, the elasticity of savings, and whether we believe the open or closed economy case is the better approximation of reality.

Both models are informative for demonstrating the sources of "stylized facts" of macro variable over the last 20 years. The closed economy case can 
mimic the movements in wages and interest rates. The open economy case, as a limiting case of perfectly elastic supply of capital, cannot mimic any price movements, but it can demonstrate the emergence of capital account surpluses we have observed. If the open economy case is the better approximation of reality, then the boomer generation should not be opposed to the status quo of social security as they clearly benefit. Baby Busters should be the most opposed since they fare poorly. However, any reforms in this case have only distributional consequences as there is no loss in productivity, and no reduction in the capital stock due to the pay-as-you-go arrangement.

If the closed economy case is the "better" approximation of reality, then it is not at all clear that reforms are necessary or socially desirable even though taxes will rise as the boomers retire. The following cohort will pay higher taxes, but they also have higher real incomes than the baby boomers, and as Bohn (1996) points out, this amounts to nothing more than taxing the relatively well of "busters" to transfer to the less well off "boomers". As Summers (1993) argues, such considerations makes proposed reforms of payas-you-go social security arrangements, to address the impending expansion of associated government spending, difficult to evaluate.

It is not clear how this (expanded) government expenditure should be financed. A reduction of social security benefits, an increase in the social security tax rate and an increase in the legal retirement age are all being considered. But, these policies are not desirable as they impose an unfair burden on the current generation. At the other extreme, we could say that the future generation has the duty to support the old through a high social security tax rate, because they enjoy the low housing prices and 
high wages which are the benefits of population decrease.

World capital markets are becoming increasingly integrated, with very few barriers to the movement of capital. Using this type of reasoning we may be tempted to disregard the closed economy case. There may, however, be a reason why the closed economy case is a more accurate description of what is happening, even if most countries are technically open economies. Many of the world's dominant economies, including the US, also have experienced baby-booms roughly corresponding to each others in timing. This means that worldwide there may be a shortage of capital, and a corresponding increase in the return to capital. An open economy in this case will see interest rates rise and the response of the domestic economy will mimic the closed economy simulations. In an extreme case for example an open economy facing exogenous interest rates such as those found in Tables 1 and 2 will exactly correspond to the closed economy case in all other variables as well.

Even if we cannot say whether the open or closed economy case is the appropriate one, we can make some comments about the arguments of commentators on pay-as-you-go arrangements. First, under any scenario, you can't have both boomers and busters worse off because of a pay-as-you-go sytem. The tragedy of the boomers, low wages and low return to savings, occurs in the closed economy case without social security. With social security, they may well do better than without. ${ }^{14}$ The following cohort pays higher taxes but still has higher consumptions than the boomers, as a result of their higher wages. In the open economy case, there can be no tragedy for

\footnotetext{
${ }^{14}$ Indeed, the current Canadian proposed reforms of accelerating the rate of increase in the CPP contribution rates with which to build up a surplus to fund future benefits, may be intergenerationally regressive and be about the worst thing to do if we care about the welfare of the baby boomers
} 
the boomers as wages should not stagnate with the inflow of capital.

One of the arguments against pay-as-you-go arrangements is that they were fine when the implicit rate of return to the plan, which is the rate of growth of the economy, is greater than the return to private investment. This was the case when the systems were first set in place but since the mid 1970's has not been true. This leads people such as Townley (1981) to conclude that we should immediately disgard pay-as-you-go systems in favour of fully funded systems. This paper makes the point that this reduction in the implied rate of return to pay-as-you-go sytems may be a result of temporary labour market distortions. In the presence of adjustment costs it may be the case that we should maintain the current system in the face of the temporary problems.

One limitation of our model is that we have only two generations alive at any given time. The real world is substantially more complex. In reality the members of the different generations are heterogenous, for example an individual born at the tail end of the baby boome may have more in common with some members of the following generation than with the rest of the boomers.

At the end of it all, the pressure for reform seems excessive. Either real wages will rise with the contribution rate as the boomers retire; or any reforms to pay-as-you-go arrangements will have largely distributional consequences, and hence are more in line with political pressure rather than the alleged economic pressures which provide the main justifications for CPP reform. 


\section{References}

[1] Berger, M. (1985): 'The Effect of Cohort Size on Earnings Growth,' Journal of Political Economy, 93, 561-573.

[2] Bohn, H. (1996): 'Welfare Across the Generations,' Contemporary Economic Policy, 14, 1-21.

[3] Boskin, M. (1978): 'Taxation, Saving, and the Rate of Interest,' Journal of Political Economy, 86, S3-S27.

[4] Bovenberg, A.L., D.P. Broer and E.W.M.T. Westerhout (1993): 'Public Pensions and Declining Fertility in a Small Open Economy: An Intertemporal Equilibrium Approach,' Public Finance 48 (Supplement), 43-59.

[5] Burbidge (1983): 'Social Security and Savings Plans in Overlapping Generations Models,' Journal of Public Economics, 21, 79-92.

[6] Fair, R, and K. Dominguez (1991): 'Effects of Changing U.S. Age Distribution on Macroeconomic Equations,' American Economic Review, 81, $1276-1394$

[7] Government of Canada (1996): Federal/Provincial Information Paper on the CPP: An Information Paper for Consultations on the Canada Pension Plan

[8] Jensen, S.E.H. and S.B. Nielsen (1993): 'Aging, Intergenerational Distribution and Public Pension Systems,' Public Finance 48 (Supplement), $29-42$. 
[9] Kotlikoff, L. (1979): 'Social Security and Equilibrium Capital Intensity,' The Quarterly Journal of Economics, 233-253.

[10] Kotlikoff, L. (1992): Generational Accounting: knowing who pays, and when, for what we spend, Maxwell MacMillan Canada, Toronto.

[11] Kotlikoff, L. (1996): 'Welfare Across the Generations,' Panel Discussion, Contemporary Economic Policy,' 14, 1-21.

[12] Manchester, J. (1989): 'The Baby Boom, Housing and Loanable Funds,' Canadian Journal of Economics, 22, 128-149.

[13] Mankiw, G., and D. Weil (1989): 'The Baby Boom, The Baby Bust, and the Housing Market,' Regional Science and Urban Economics, 19, 235-258.

[14] Pesando, J.E. (1993): 'Policy Issues: The Pension Crisis,' Paper Presented at the conference titled "The Impact of an Aging Population on Society" held at the University of Calgary, March 15-16, 1993.

[15] Richardson, D. (1994): 'Social Security Options: Validation, Offset, or Return to Pay-as-You-Go,' Discussion Paper 94-20, University of British Columbia.

[16] Stapleton, D. and D. Young (1984): 'The Effects of Demographic Changes on the Distribution of Wages, 1967-1990,' Journal of Human Resources, 19(2), 175-201.

[17] Summers, L.H. (1993): 'Keynote Speech: Population Problem Confronted by the World Economy - A Summary,' Public Finance 48 (Supplement), 1-3. 
[18] Townley, P. (1981): 'Public Choice and the Social Insurance Paradox: A Note,' Canadain Journal of Economics, 14(4), 712-717.

[19] Welch, F. (1979): 'Effects of Cohort Size on Earnings Growth: A reexamination of the Evidence,' Journal of Political Economy, 87, S65-S97.

[20] Weldon, J. (1976): 'On the Theory of Intergenerational Transfers,' Canadian Journal of Economics, 9, 559-579.

[21] Wolfson, M, and B. Murphy (1996): 'Aging and the Public Sector: Retrospect and Prospect' Paper Presented to Conference on Reform of the Retirement Income System, Queen's University.

[22] Yoo, P. (1994): 'Boom or Bust? The Economic Effects of the Baby Boom,' Review, Federal Reserve Bank of St. Louis, 76 (5), 13-22. 